Conclusion: AS-related work disability and healthcare resource utilization have an enormous economic impact in Portugal. Investment in strategies that encourage early referral, diagnosis and treatment is fundamental to mitigate such burden.

Disclosure of Interests: None declared

DOI: 10.1136/annrheumdis-2019-eular.3400

\section{THU0634 PHYSICIAN PERCEPTIONS OF BIOLOGICS VERSUS THEIR BIOSIMILAR COUNTERPARTS IN RHEUMATOLOGY: A MULTICOUNTRY STUDY IN EUROPE}

Casey Zhang ${ }^{1}$, Denise Baldock ${ }^{2}$, Elizabeth Baynton ${ }^{2} .{ }^{1} / p s o s$, New York, United States of America; ${ }^{2}$ Ipsos, London, United Kingdom

Background: Following LOE for the originator brand of etanercept in 2016 and the subsequent launch of its first biosimilar version, several other biosimilars have arrived in the rheumatoid arthritis treatment space. Due to their potential for reducing healthcare spend and their supposed equivalence, biosimilars are expected to be of rising relevance and impact in the following years. 12 biosimilar brands of biologic originator treatments are now available in Europe to treat rheumatoid arthritis; it will be crucial to understand physician perceptions of biosimilars relative to branded products and the impact such views have on potential prescribing decisions.

Objectives: The objective of the study was to assess perceptions of efficacy and safety for biosimilars relative to branded biologic originator products among treating Rheumatologists in the EU5 countries (United Kingdom (UK), France (FR), Italy (IT), Spain (SP) and Germany (DE)). Methods: A cross-sectional survey was conducted in Q3 2018 in the EU5 among national, regional and hospital physicians who had been practicing between 3-30 years. Respondents completed a Physician Perceptual Questionnaire online, which assessed the overall perception of biologic brands and anti-TNF biosimilars, important attributes for treatments, and specific barriers to prescribing them. Data were analyzed using descriptive statistics.

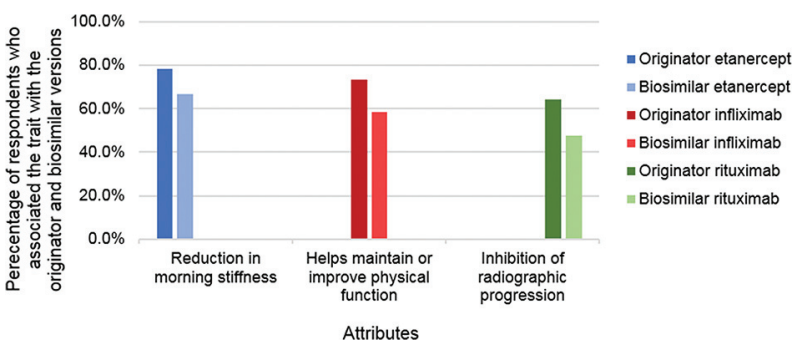

Results: A total of 261 rheumatologists in the EU5 were recruited as part of the study (with almost equal numbers of rheumatologists representing each EU5 country). Treating rheumatologists were practicing for an average of 17.4 years, mainly in teaching hospitals $(50.2 \%)$ and urban hospitals $(20.7 \%)^{1}$. Physicians consistently expressed greater satisfaction for branded products, with $73.9 \%$ (range: $63.5 \%$ DE to $90.6 \% \mathrm{FR}$ ) of physicians having rated satisfaction with the originator brand of etanercept as a 6 or 7 (on a 7-point scale where 7 corresponded to highest satisfaction), compared to only $37.5 \%$ for biosimilar etanercept (range: $28.6 \%$ IT to $51.9 \% \mathrm{DE})^{1}$. When asked about specific attributes related to RA treatments, $64.4 \%$ of our sampled rheumatologists associated the originator brand of rituximab with 'Inhibition of radiographic progression' (range: $55.1 \%$ IT to $81.1 \% \mathrm{FR}$ ) - versus $47.5 \%$ association for biosimilar rituximab (range: $32.7 \%$ IT to $62.3 \% \mathrm{FR})^{1}$. $73.2 \%$ of physicians associated the originator brand of infliximab with 'helps maintain or improve physical function' (range: $55.8 \%$ DE to $87.0 \%$ ES) compared to $58.6 \%$ of biosimilar infliximab (range: $44.9 \%$ IT to $67.9 \% \mathrm{FR})^{1}$. For 'reduction in morning stiffness', $78.5 \%$ of our rheumatologists associated it with originator etanercept (range: $65.4 \%$ DE to $88.7 \%$ FR) versus only $66.7 \%$ for biosimilar etanercept (range: $55.1 \%$ IT to $81.1 \%$ FR) ${ }^{1}$.

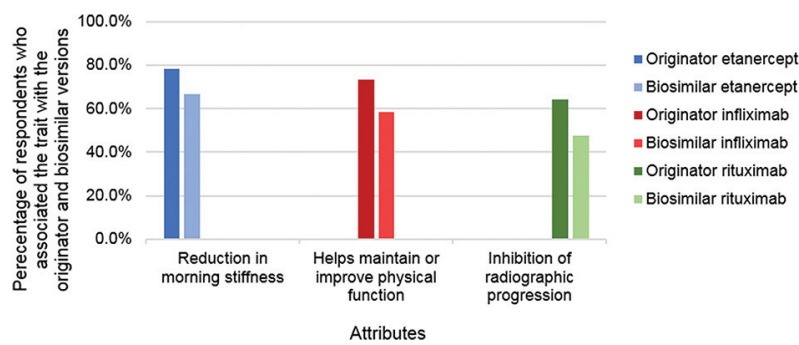

Figure: EU5 Physician Perceptions: Attribute associations for branded versus biosimilar products

Conclusion: Biosimilars score lower on overall satisfaction and are less frequently associated with specific efficacy attributes relative to branded products. This is possibly due to their relatively short time in clinical practice, and the resulting lack of experience and supporting data compared to the older branded equivalents. Proof of concept may be essential to close the perceptual gap that still exists between branded products and biosimilars.

\section{REFERENCES:}

[1] Ipsos RA Therapy Monitor (261 sampled rheumatologists reporting on RA patients in EU5 in Q3 2018)

Disclosure of Interests: None declared DOI: 10.1136/annrheumdis-2019-eular.6925

\section{THU0635 REAL WORLD PHYSICIAN SATISFACTION WITH SECUKINUMAB IN PSORIATIC ARTHRITIS AND ANKYLOSING SPONDYLITIS IN EUROPE}

Elizabeth Holdsworth ${ }^{1}$, Nicola Booth ${ }^{1}$, Steve Lobosco ${ }^{1}$, Olivia Massey ${ }^{1}$, Amie Scott ${ }^{2}$, Haijun Tian ${ }^{3}$, Dorothy Keininger ${ }^{4}$. ${ }^{1}$ Adelphi Real World, Manchester, United Kingdom; ${ }^{2}$ KMK Consulting Inc, Morristown, United States of America;

${ }^{3}$ Novartis Pharmaceuticals Corporation, East Hanover, United States of America; ${ }^{4}$ Novartis Pharma AG, Basel, Switzerland

Background: Psoriatic arthritis (PsA) and ankylosing spondylitis (AS) can lead to reduced physical functioning and quality of life. Secukinumab has demonstrated clinical benefits in PsA and AS, however little is known about physician satisfaction with its ability to control disease in the real world.

Objectives: Assess physician satisfaction with secukinumab's ability to control disease in a real-world setting.

Methods: This was a cross-sectional survey of rheumatologists and dermatologists (PsA only) in France, Germany, Italy, Spain, and UK. Data were collected from Jun-Aug 2018 via physician-completed patient record forms. Patients receiving any treatment were included in the survey. Patients receiving secukinumab $>1$ month were included in this analysis. Physicians rated satisfaction on a 5-point scale (Very satisfied to very dissatisfied), a binary variable of satisfied/not satisfied was created by grouping "Very satisfied" and "Satisfied" responses as satisfied and "Neutral", "Dissatisfied", and "Very dissatisfied" as not satisfied. Data were reported by disease, then stratified by overall physician-rated disease severity (mild/moderate/severe) at initiation of secukinumab, prior biologic use, treatment duration, and concomitant medication.

Results: $438 \mathrm{PsA}$ and 277 AS patients were receiving secukinumab $>1$ month at time of data collection. Patient mean age was 46.9 years (48.2 PsA, 44.8 AS) with $35.2 \%$ female $(41.8 \%$ PsA; $24.9 \%$ AS). On average, patients had received secukinumab for 8.8 months (9.2 PsA; 8.2 AS). At secukinumab initiation, $44.2 \%$ of patients were rated by their physician as severe vs. $3.5 \%$ at the current consultation $(39.3 \%$ vs. $2.7 \%$ PsA; $52.0 \%$ vs. $4.7 \%$ AS)

Overall, $87.6 \%$ of physicians were satisfied with the ability of secukinumab to control disease $(87.9 \%$ PsA; $86.3 \%$ AS). Physicians report high satisfaction across each stratification (Table 1). 
Table 1. Population characteristics, and physician reported satisfaction with secukinumab

\begin{tabular}{|c|c|c|c|c|}
\hline & \multicolumn{2}{|c|}{ Population characteristics } & \multicolumn{2}{|c|}{ Satisfaction level } \\
\hline & $\begin{array}{c}\text { N (\%) PsA patients } \\
\text { in each category } \\
(n=438)\end{array}$ & $\begin{array}{c}N(\%) \text { AS } \\
\text { patients in } \\
\text { each category } \\
(n=277)\end{array}$ & $\begin{array}{c}\text { N (\%) PsA } \\
\text { physicians } \\
\text { satisfied } \\
(n=438)\end{array}$ & $\begin{array}{c}\mathrm{N}(\%) \text { AS } \\
\text { physicians } \\
\text { satisfied } \\
(\mathrm{n}=277)\end{array}$ \\
\hline $\begin{array}{l}\text { Overall } \\
\text { satisfaction }\end{array}$ & - & - & $385(87.9)$ & $239(86.3)$ \\
\hline Severity at & $28(6.4)$ & $5(1.8)$ & $18(64.3)$ & $4(80.0)$ \\
\hline initiation* & $236(54.3)$ & $128(46.2)$ & $210(89.0)$ & $109(85.2)$ \\
\hline $\begin{array}{l}\text { Mild } \\
\text { Moderate } \\
\text { Severe }\end{array}$ & $171(39.3)$ & $144(52.0)$ & $155(90.6)$ & $126(87.5)$ \\
\hline Prior biologic & $191(43.6)$ & $147(53.1)$ & $155(81.2)$ & $118(80.3)$ \\
\hline $\begin{array}{l}\text { use } \\
\text { Bio- } \\
\text { experienced } \\
\text { patients } \\
\text { Bio-naive } \\
\text { patients }\end{array}$ & $247(56.4)$ & $130(47.9)$ & $230(93.1)$ & $121(93.1)$ \\
\hline Secukinumab & $82(18.7)$ & $72(26.0)$ & $56(68.3)$ & $48(66.7)$ \\
\hline duration & $120(27.4)$ & $68(24.5)$ & $108(90.0)$ & 61 (89.7) \\
\hline $\begin{array}{l}1-4 \text { months } \\
>4-6 \text { months } \\
>6 \text { months }\end{array}$ & $236(53.9)$ & $137(49.5)$ & $221(93.6)$ & $130(94.9)$ \\
\hline Concomitant & $236(53.9)$ & $117(42.2)$ & $214(90.7)$ & $103(88.0)$ \\
\hline medication & $104(23.7)$ & $113(40.8)$ & $89(85.6)$ & $95(84.1)$ \\
\hline $\begin{array}{l}\text { Monotherapy } \\
\text { Combination } \\
\text { with a non- } \\
\text { csDMARD } \\
\text { Combination } \\
\text { with a } \\
\text { csDMARD }\end{array}$ & $98(22.4)$ & $47(17.0)$ & $82(83.7)$ & $41(87.2)$ \\
\hline
\end{tabular}

${ }^{*}$ PsA base size $=435$

Conclusion: This study provides insight into physician satisfaction with secukinumab in a real-world clinical setting. Physicians reported being highly satisfied with the ability of secukinumab to control PsA and AS disease, regardless of patient population subgroups.

Disclosure of Interests: Elizabeth Holdsworth Employee of: Adelphi Real World, Nicola Booth Employee of: Adelphi Real World, Steve Lobosco Employee of: Adelphi Real World, Olivia Massey Employee of: Adelphi Real World, Amie Scott Consultant for: Novartis Pharmaceuticals Corporation, Haijun Tian Shareholder of: Novartis Pharmaceutical Corporations, Employee of: Novartis Pharmaceutical Corporations, Dorothy Keininger Shareholder of: Novartis, Employee of: Novartis DOI: 10.1136/annrheumdis-2019-eular.4167

\section{THU0636 HIGHER SOCIAL MEDIA USER STICKINESS ON SELF- MANAGEMENT SYSTEM MAY IMPROVE THE REMISSION RATE OF PATIENTS WITH ANKYLOSING SPONDYLITIS}

Xiaojian Ji, Jian Zhu, Jianglin Zhang, Feng Huang, SpAMS co-authors. Chinese PLA General Hospital, Department of Rheumatology, Beijing, China

Background: With the advence of mobile health technologies, it is possible to set up economic management systems to improve health care. By using a Smart-phone Spondyloarthritis Management System (SpAMS), the Chinese Ankylosing Spondylitis (AS)/Spondyloarthritis Prospective Imaging Cohort (CASPIC) was launched.

Objectives: To explore the improvement of disease management and cost effectiveness of SpAMS for Chinese patients with AS

Methods: Patients enrolled in the CASPIC cohort who fulfilled the 1984 modified New York criteria and with at least 2 evaluations of Ankylosing Spondylitis Disease Activity Score (ASDAS) were included in this analysis. All physician-reported assessments were collected at the Chinese People's Liberation Army General Hospital using SpAMS in Beijing. The disease activity states were defined according to ASDAS1, which separated inactive disease (ID) from low disease activity (LDA) by 1.3, LDA from high disease activity (HDA) by 2.1, and HDA from very high disease activity (VHDA) by 3.5. According to ASDAS at the baseline visits and final visits, patients were divided into four groups (Figure 1): maintainer of ID/LDA, patients with relapse, maintainer of active disease, and new achiever of ID/LDA.

Results: From April 2016 to April 2018, 1201 patients with AS were enrolled in CASPIC. 4659 patient self-assessments were completed, including 3304 pre-visit assessments and 1355 assessments during the follow-up interval. After online consultation, $29.1 \%$ of clinic visits to a tertiary hospital were considered unnecessary and could be solved in the primary care hospital. The time and cost of each patient's journey to Beijing were calculated based on the location of each patient. For the 1037 $(86.3 \%)$ patients who lived outside the vicinity of Beijing, at least an average of 5.3 hours and $327.4 \mathrm{RMB}$ for each person (USD: RMB $=1: 6.418$ ) for traffic time and expenses were saved, which equaled to $16 \%$ of the Chinese monthly disposable personal income (data in 2016).

\begin{tabular}{|c|c|c|c|c|c|c|}
\hline \multirow[t]{2}{*}{ Characteristics } & \multicolumn{3}{|c|}{$\begin{array}{c}\text { ID/LDA at baseline } \\
(n=445,57.2 \%)\end{array}$} & \multicolumn{3}{|c|}{$\begin{array}{l}\text { Active at baseline } \\
(n=332,42.7 \%)\end{array}$} \\
\hline & $\begin{array}{c}\text { Maintainers } \\
\text { of ID/LDA } \\
\text { ( } n=410 \\
92.1 \%)\end{array}$ & $\begin{array}{l}\text { Patients } \\
\text { with } \\
\text { relapse } \\
(n=35 \\
7.9 \%)\end{array}$ & $P$ value & $\begin{array}{c}\text { Maintainers } \\
\text { of active } \\
\text { disease } \\
(n=127 \\
38.2 \%)\end{array}$ & $\begin{array}{c}\text { New } \\
\text { achievers } \\
\text { of ID/LDA } \\
(\mathrm{n}=205 \text {, } \\
61.7 \%)\end{array}$ & $P$ value \\
\hline $\begin{array}{l}\text { Age, mean (s. } \\
\text { D.), years }\end{array}$ & $30.2(9.1)$ & $29.8(7.6)$ & 0.785 & $30.8(8.6)$ & $30.6(8.3)$ & 0.816 \\
\hline $\begin{array}{l}\text { Disease } \\
\text { duration, mean } \\
\text { (s.D.), years }\end{array}$ & $7.6(6.2)$ & $7.3(5.6)$ & 0.787 & $9.0(6.1)$ & $9.3(6.1)$ & 0.714 \\
\hline $\begin{array}{l}\text { Number of self- } \\
\text { assessments, } \\
\text { mean (s.D.) }\end{array}$ & $5.0(2.7)$ & $3.3(1.8)$ & $<0.001^{*}$ & $4.5(2.5)$ & $5.6(3.1)$ & $<0.001^{*}$ \\
\hline Male sex,\% & 79.8 & 88.6 & 0.207 & 89.8 & 83.9 & 0.133 \\
\hline $\begin{array}{l}\text { ASDAS at } \\
\text { baseline, mean } \\
\text { (S.D.) }\end{array}$ & $1.4(0.5)$ & $1.5(0.4)$ & $0.031^{*}$ & $3.2(0.8)$ & $3.0(0.8)$ & 0.134 \\
\hline Smoker,\% & 24.7 & 40.0 & $0.047^{*}$ & 44.0 & 32.8 & $0.042^{*}$ \\
\hline $\begin{array}{l}\text { NSAIDs at } \\
\text { baseline, } \%\end{array}$ & 98.1 & 99.8 & 0.448 & 97.9 & 99.4 & 0.263 \\
\hline $\begin{array}{l}\text { TNFi at } \\
\text { baseline,\% }\end{array}$ & 19.2 & 13.8 & 0.479 & 24.5 & 29.8 & 0.359 \\
\hline $\begin{array}{l}\text { DMARDs at } \\
\text { baseline, } \%\end{array}$ & 64.0 & 72.4 & 0.363 & 66.0 & 68.5 & 0.679 \\
\hline $\begin{array}{l}\text { TNFi during } \\
\text { follow-up } \\
\text { period }^{\mathrm{a}} \%\end{array}$ & 29.9 & 27.3 & 0.755 & 32.3 & 45.6 & $0.016^{*}$ \\
\hline
\end{tabular}

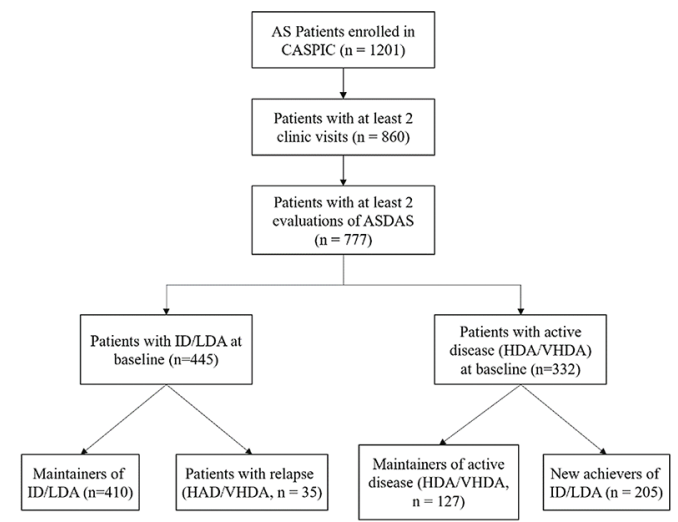

Figure 1. Flow chart of participants in the study

Abbreviation: ID: inactive disease: LDA: low disease activity; HDA: high disease activity; VHDA: very high disease activity

Of these patients enrolled in CASPIC, 777 patients had at least 2 evalu ations of ASDAS. The rate of patients with ID/LDA was $57.2 \%$ at baseline and increased significantly to $79.2 \%$ with a mean (SD) follow-up of 13.3 (5.9) months (Table 1). Compared with patients who relapsed, those that maintained the ID/LDA had more patient assessments $[5.0$ (2.7) vs 3.3 (1.8), $P<0.001]$. The new achievers of ID/LDA also completed online patient assessments more frequent [5.6 (3.1) vs 4.5 (2.5), $\mathrm{P}<$ 0.001] compared to patients who maintained active disease.

Conclusion: Higher social media user stickiness on self-management system may improve the remission rate of AS patients. SpAMS could serve as a cost- and time-saving specialty care online platform for patients with AS.

\section{REFERENCES:}

[1] Machado PM, Landewé R, Heijde Dvd. Ankylosing Spondylitis Disease Activity Score (ASDAS): 2018 update of the nomenclature for disease activity states. Ann Rheum Dis 2018:annrheumdis-2018-213184 